\title{
Black Hole Problem in AODV Routing Protocol in MANET
}

\author{
Krunal S Bhavsar ${ }^{1}$, Dr. Kamaljit I Lakhtaria ${ }^{2}$ \\ Research Scholar, JJTU India \\ Associate Professor, Gujarat University, India
}

\begin{abstract}
A mobile Ad-hoc network (MANET) is a dynamic multi hop wireless network established by a group of nodes in which there is no central administration. Due to mobility of nodes and dynamic network topology, the routing is one of the most important challenges in ad-hoc networks. Several routing algorithms for MANETs have been proposed by the researchers which have been classified into various categories, however, the most prominent categories are proactive, reactive and hybrid. The performance comparison of routing protocols for MANETs has been presented by other researcher also, however, none of these works considers proactive, reactive and hybrid protocols together. In this paper, the performance of proactive (DSDV), reactive (DSR and AODV) and hybrid (ZRP) routing protocols has been compared. The performance differentials are analyzed on the basis of throughput, average delay, routing overhead and number of packets dropped with a variation of number of nodes, pause time and mobility. In MANET each and every mobile node is assumed to be moving with more or less relative speed in arbitrary direction. Because of that there is no long term guaranteed path from any one node to other node. MANET have very enterprising use in emergency scenarios like military operations \& disaster relief operation where there is need of communication network immediately following some major event, or some temporary requirement like conference \& seminar at new place where there is no earlier network infrastructure exist and need alternative solution
\end{abstract}

Keywords: MANET, AODV, DSR, SDV, RREQ

\section{Introduction}

Mobile Ad- Hoc Networks (MANETs) have evolved rapidly in the field of wireless networks. These are infrastructure less networks where routers and hosts providing access points are not fixed. In case if a mobile user away from an access point needs to send or receive data packets, this is facilitated by radio transmission and receiving ability of mobile phone with help of other nearby existing nodes creating dynamic networks. In literature MANETs are defined as "an autonomous system of mobile routers (and associated hosts) connected by wireless links - the union of which form an arbitrary graph"

A network can be characterized as wired or wireless. Wireless can be distinguished from wired as no physical connectivity between nodes is needed. Routing is an activity or a function that connects a call from origin to destination in telecommunication networks and also plays an important role in architecture, design and operation of networks. Ad-hoc networks are wireless networks where nodes communicate with each other using multi-hop links. There is no stationary infrastructure or base station for communication. Each node itself acts as a router for forwarding and receiving packets to/from other nodes. Routing in ad-networks has been a challenging task ever since the wireless networks came into existence. The major reason for this is the constant change in network topology because of high degree of node mobility. A number of protocols have been developed for accomplish this task. The wireless mobile ad hoc nature of MANETs brings new security challenges to the network design. As the wireless medium is vulnerable to eavesdropping and ad hoc network functionality is established through node cooperation, mobile ad hoc networks are intrinsically exposed to numerous security attacks. Devices used in these networks have restrictions on the power source in order to maintain portability, size and weight of the device

\section{The Black Hole Problem in Current AODV Protocol}

AODV is a vital on-interest directing protocol that makes courses just when craved by the source hub. At the point when a hub obliges a course to a destination, it starts a course revelation process inside of the system. It shows a course ask for (RREQ) bundle to its neighbors, which then forward the solicitation to their neighbors, et cetera, until either the destination or an intermediate hub with a "sufficiently new" course to the destination is found. In this procedure the intermediate hub can answer to the RREQ bundle just in the event that it has a sufficiently new course to the destination. Once the RREQ achieves the destination or an intermediate hub with a sufficiently crisp course, the destination or moderate hub reacts by unicasting a course answer (RREP) parcel back to the neighbor from which it initially got the RREQ. Subsequent to selecting and setting up a course, it is kept up by a course support technique until either the destination gets to be difficult to reach along each way from the source or the course is no more fancied.

\section{Our Proposed Methodology}

In this segment new procedure is portrayed to demonstrate the contrast between the E-AODV and the AODV steering conventions amid transmission with the accompanying straightforward topology. There are four hubs in this system, and the beginning topology is a 


\section{International Journal of Science and Research (IJSR) \\ ISSN (Online): 2319-7064}

Index Copernicus Value (2013): 6.14 | Impact Factor (2014): 5.611

framework and the strategy. As per the situation, toward the start of the transmission of hubs, the two sets are not impedance with one another. At 10s, Node 2 moves towards the heading of Node 0 with a pace of $10 \mathrm{~m} / \mathrm{s}$. The separation between Node 0 and Node 2 gets to be littler and littler, and at time $15 \mathrm{~s}$, these two hubs start to be in every other bearer detecting reach, which implies that these two hubs start to have the same channel. The most extreme data transmission of the channel is around 3.64 Mbps. In AODV, where there is no QoS prerequisite, when Node 2 is in the impedance scope of Node 0 , traffics are continued and a few parcels are lost amid the transmission, though, in E-AODV, the QoS is guaranteed. At the point when the guaranteed information rate can't be fulfilled any more, movement of Node 2 is ceased on the double. From this case, we could see that the E-AODV accomplished the capacity of guaranteeing the QoS not just at.

Table 3: Scenario descriptions for proposed topology

\begin{tabular}{|c|c|c|c|c|}
\hline $\begin{array}{c}\text { Node } \\
\text { position }\end{array}$ & $\begin{array}{c}\text { Node 0 } \\
(50,250)\end{array}$ & $\begin{array}{c}\text { Node 1 } \\
(50,100)\end{array}$ & $\begin{array}{c}\text { Node 2 } \\
(650,250)\end{array}$ & $\begin{array}{c}\text { Node 3 } \\
(50,100)\end{array}$ \\
\hline $\begin{array}{c}\text { Node } \\
\text { movement }\end{array}$ & Node ID & $\begin{array}{c}\text { Time that } \\
\text { node begins } \\
\text { to move }\end{array}$ & $\begin{array}{c}\text { Movement } \\
\text { direction }\end{array}$ & $\begin{array}{c}\text { Movement } \\
\text { speed }\end{array}$ \\
\hline Traffic & Node 2 & $10 \mathrm{~s}$ & $(550,250)$ & $10 \mathrm{~m} / \mathrm{s}$ \\
\hline & $\begin{array}{c}\text { Node 1- } \\
\text { node 0 }\end{array}$ & $6 \mathrm{~s}-18 \mathrm{~s}$ & CBR & $\begin{array}{c}\text { Required } \\
\text { data Rate }\end{array}$ \\
\hline & $\begin{array}{c}\text { Node 2- } \\
\text { Node 3 }\end{array}$ & $6 \mathrm{~s}-18 \mathrm{~s}$ & CBR & $2 \mathrm{Mbps}$ \\
\hline
\end{tabular}

\section{Metrics For Performance Comparison}

A. Packet delivery fraction:-The ratio of the data packets delivered to the destinations to those generated by the CBR sources. It specifies the packet loss rate, which limits the maximum throughput of the network

B. End-to-end Delay- This metric represents average end-to-end delay and indicates how long it took for a packet to travel from the source to the application layer of the destination. It includes all possible delay caused by buffering during route discovery latency, transmission delays at the MAC, queuing at interface queue, and propagation and transfer time. It is measured in seconds.

C. Throughput:- Throughput is total packets successfully delivered to individual destination over total time divided by total time.

The first two metrics are the most important for besteffort traffic. The routing load metric evaluates the efficiency of the routing protocol. Note, however, that these metrics are not completely independent. For example, lower packet delivery fraction means that the delay metric is evaluated with fewer samples. In the conventional wisdom, the longer the path lengths, the higher the probability of a packet drops. Thus, with a lower delivery fraction, samples are usually biased in favor of smaller path lengths and thus have less delay.

Table 4: Protocols Comparison

\begin{tabular}{|c|c|c|c|c|c|c|}
\hline Properties\Protocols & ASDV & AODV & DSR & ZRP & TORA/IMEP & CBRP \\
\hline Loop-free & Yes & Yes & Yes & Yes & No, short lived loops & Yes \\
\hline Multiple routes & No & No & Yes & No & Yes & Yes \\
\hline Distributed & Yes & Yes & Yes & Yes & Yes & Yes \\
\hline Reactive & No & Yes & Yes & Partially & Yes & Yes \\
\hline Unidirectional link Support & No & No & No & No & No & No \\
\hline QoS support & No & No & No & No & No & No \\
\hline Multicast & No & Yes & No & No & No & No \\
\hline Security & No & No & No & No & No & No \\
\hline Power Conservation & No & No & No & No & No & No \\
\hline Periodic broadcasts & Yes & Yes & No & Yes & Yes & Yes \\
\hline Requires reliable or Sequenced data & No & No & No & No & Yes & No \\
\hline
\end{tabular}

\section{Simulation Model}

System Simulator (Version 2.29), broadly known as NS2, is just an occasion driven reenactment apparatus that has demonstrated valuable in examining the dynamic way of correspondence systems. Reenactment of wired and in addition remote system capacities and conventions (e.g., steering calculations, TCP, UDP) should be possible utilizing NS2. A reenactment study was completed to assess the execution of MANET steering conventions for example, DSDV, AODV and DSR taking into account the measurements throughput, parcel conveyance proportion and normal end-to-end delay with the accompanying parameters:
Table 5.1 DSDV, AODV and DSR Parameter

\begin{tabular}{|c|c|}
\hline Parameter & Value \\
\hline Radio model & Two Ray Ground \\
\hline Protocols & DSDV,AODV,DSR \\
\hline Packet size & 512 bytes \\
\hline Max speed & $10 \mathrm{~m} / \mathrm{s}$ \\
\hline Area & $500 \times 500$ \\
\hline Traffic Source & Constant Bit Rate \\
\hline Number of nodes & $50,75,100$ \\
\hline Application & FTP \\
\hline MAC & Mac/802_11 \\
\hline Simulation time (Sec) & $20,40,60,80 \& 100$ \\
\hline
\end{tabular}




\section{International Journal of Science and Research (IJSR) \\ ISSN (Online): 2319-7064}

Index Copernicus Value (2013): 6.14 | Impact Factor (2014): 5.611

\subsection{Performance Indices}

The following performance metrics are considered for evaluation: a) Packet delivery ratio: The ratio between the number of packets originated by the $\mathrm{CBR}$ sources and the number of packets received by the CBR sink at the final destination. It describes the loss rate seen by the protocol

\begin{tabular}{|c|l|l|l|l|l|l|l|l|l|}
\hline \multirow{2}{*}{$\begin{array}{c}\text { Pause Time } \\
\text { (Sec.) }\end{array}$} & \multicolumn{9}{|c|}{ PSotocol } \\
\cline { 2 - 10 } & \multicolumn{3}{|c|}{ DSDV } & \multicolumn{3}{c|}{ AODV } & \multicolumn{1}{c|}{ DSR } \\
\hline \multirow{3}{*}{20} & $50 \mathrm{~N}$ & $75 \mathrm{~N}$ & $100 \mathrm{~N}$ & $50 \mathrm{~N}$ & $75 \mathrm{~N}$ & $100 \mathrm{~N}$ & $50 \mathrm{~N}$ & $75 \mathrm{~N}$ & $100 \mathrm{~N}$ \\
\cline { 2 - 10 } 40 & 97.6169 & 96.8661 & 80 & 99.0667 & 99.061 & 99.1886 & 99.1919 & 99.1909 & 99.1896 \\
60 & 98.8569 & 98.5653 & 96.6102 & 99.1201 & 99.1093 & 99.1795 & 99.2434 & 99.2213 & 99.2031 \\
80 & 98.4053 & 98.1191 & 96.4844 & 99.3528 & 99.3466 & 99.384 & 99.4335 & 99.4166 & 99.404 \\
100 & 98.8518 & 97.9306 & 97.2525 & 99.488 & 99.4843 & 99.5086 & 99.5467 & 99.5335 & 99.5233 \\
& 98.4413 & 98.0971 & 97.4224 & 99.5764 & 99.5739 & 99.5907 & 99.6223 & 99.6113 & 99.6028 \\
\hline
\end{tabular}

Table no. 5.2 Packet delivery ratio

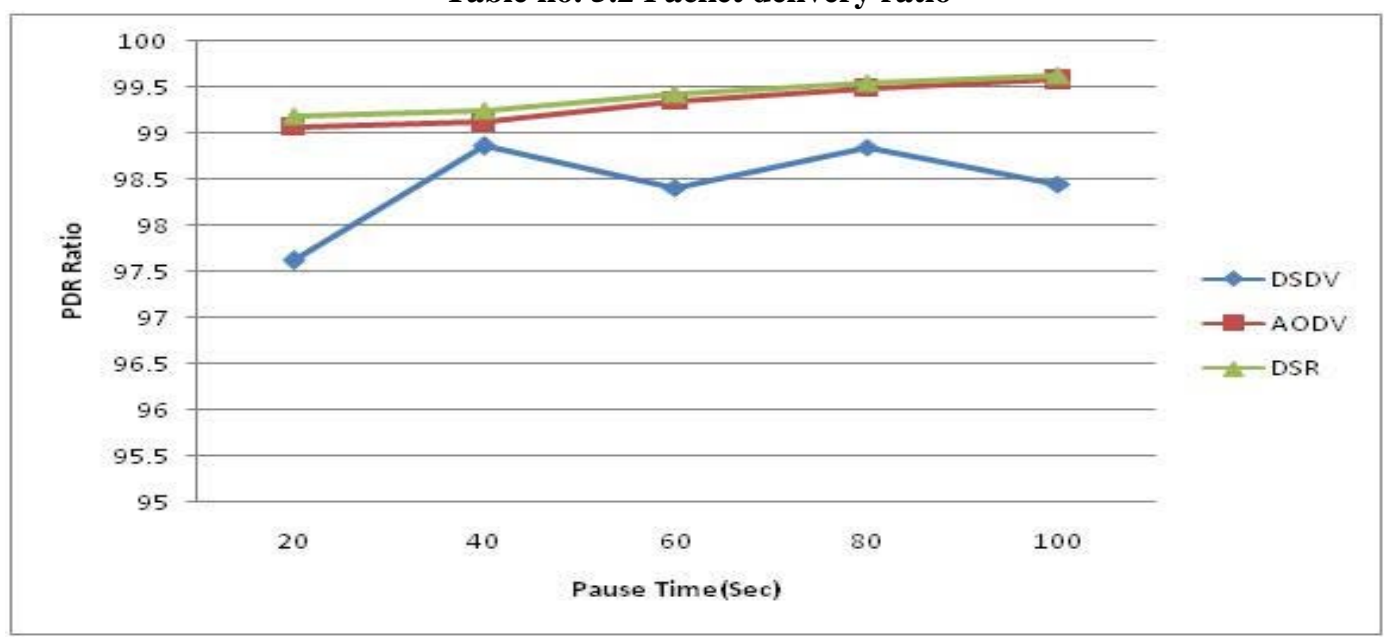

Graph. 5.2 Packet delivery ratio

b) Throughput:- It is obvious from the outcomes that throughput of AODV is better when contrasted with different conventions. In addition, the adjustment in the delay worth does not have any impact on AODV execution. For the most part, for every one of the conventions, by expanding the quantity of nodes, throughput additionally increments. In DSDV, at first (before the joining of roots), a few parcels are sent and get dropped, along these lines, it has low throughput when contrasted with AODV and DSR. With delay esteem 200 and number of hubs 10, the throughput of DSDV is zero. The throughput of ZRP does not change even on changing the respite esteem or velocity or the quantity of hubs. The purpose for this marvel may be the settled zone range. On changing the delay esteem, the throughput of DSR has a swaying conduct. One conceivable reason is that DSR uses course reserve and the courses put away in the store may get to be stale after at some point. Be that as it may, by expanding the speed, the throughput of DSR declines. This can be because of the portability of hubs which may expand the possibilities of way failure. Phenomenon may be the altered zone sweep. On changing the interruption esteem, the throughput of DSR has a wavering conduct. One conceivable reason is that DSR uses course reserve and the courses put away in the store may get to be stale after at some point. In any case, by expanding the speed, the throughput of DSR reductions. This can be because of the versatility of hubs which may expand the shots of way disappointment. 


\section{International Journal of Science and Research (IJSR) \\ ISSN (Online): 2319-7064}

Index Copernicus Value (2013): 6.14 | Impact Factor (2014): 5.611

\begin{tabular}{|c|c|c|c|c|c|c|c|c|c|}
\hline \multirow{2}{*}{$\begin{array}{c}\text { Pause Time } \\
\text { (Sec.) }\end{array}$} & \multicolumn{9}{|c|}{ Protocol } \\
\hline & \multicolumn{3}{|c|}{ DSDV } & \multicolumn{3}{|c|}{$A O D V$} & \multicolumn{3}{|c|}{ DSR } \\
\hline & $50 \mathrm{~N}$ & $75 \mathrm{~N}$ & $100 \mathrm{~N}$ & $50 \mathrm{~N}$ & $75 \mathrm{~N}$ & $100 \mathrm{~N}$ & $50 \mathrm{~N}$ & $75 \mathrm{~N}$ & $100 \mathrm{~N}$ \\
\hline 20 & 314933 & 304192 & 1738.67 & 599851 & 692565 & 691435 & 680597 & 680597 & 680597 \\
\hline 40 & 326862 & 315232 & 90390.9 & 547095 & 581015 & 587314 & 579319 & 575991 & 579794 \\
\hline 60 & 230359 & 207078 & 57521.5 & 474272 & 495703 & 499404 & 492096 & 490886 & 493155 \\
\hline 80 & 260288 & 242423 & 127322 & 439949 & 455665 & 458831 & 451614 & 450615 & 452834 \\
\hline 100 & 276990 & 260298 & 166929 & 419988 & 432664 & 435074 & 428177 & 426776 & 429315 \\
\hline
\end{tabular}

Table no. 5.2.b Throughput

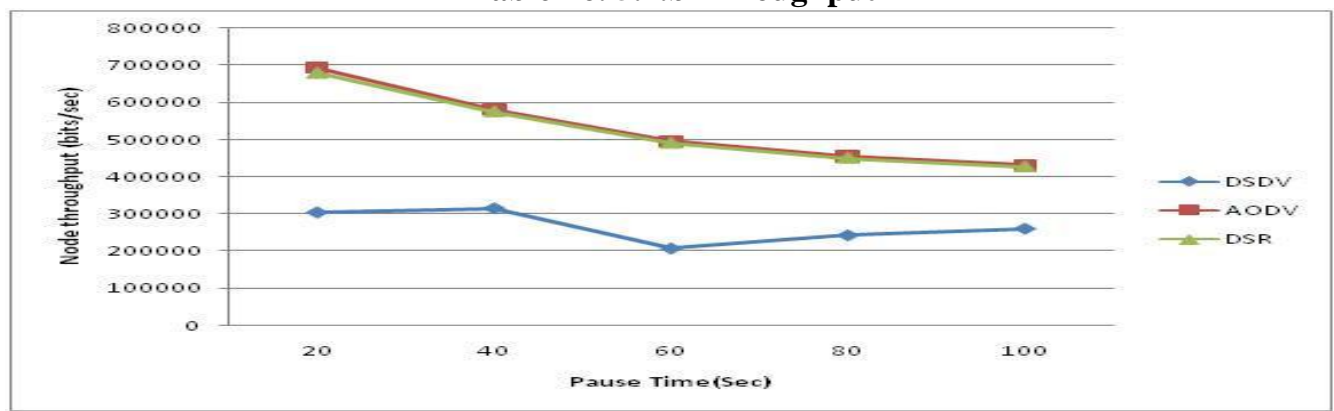

Graph no. 5.2.b Throughput

c) Avg. End-to-End Delay:-This includes all possible delays caused by buffering during route discovery latency, queuing at the interface queue, retransmission on delays at MAC, and propagation and transfer. Various applications require different levels of packet delay. Delay sensitive applications such as voice require a low average delay in the network whereas other applications such as FTP may be tolerant to delays up to a certain level. MANETs are characterized by node mobility, packet retransmissions due to weak signal strengths between nodes, and connection tearing and making. These cause the delay in the network to increase. The End-toEnd delay is therefore a measure of how well a routing protocol adapts to the various constraints in the network and represents the reliability of the routing protocol. On average case, DSR shows better performance than AODV but worse than DSDV. As AODV needs more time in route discovery, it produces more End-to-End delay from the above study on End-to-End delay, DSDV has high reliability than AODV and DSR.

\begin{tabular}{|c|c|c|c|c|c|c|c|c|c|}
\hline \multirow{2}{*}{$\begin{array}{c}\text { Pause Time } \\
\text { (Sec.) }\end{array}$} & \multicolumn{9}{|c|}{ Protocol } \\
\hline & \multicolumn{3}{|c|}{ DSDV } & \multicolumn{3}{|c|}{$A O D V$} & \multicolumn{3}{|c|}{ DSR } \\
\hline & $50 \mathrm{~N}$ & $75 \mathrm{~N}$ & $100 \mathrm{~N}$ & $50 \mathrm{~N}$ & $75 \mathrm{~N}$ & $100 \mathrm{~N}$ & $50 \mathrm{~N}$ & $75 \mathrm{~N}$ & $100 \mathrm{~N}$ \\
\hline 20 & 0.12090 & 0.12271 & 0.32939 & 0.19027 & 0.15404 & 0.17863 & 0.09408 & 0.16907 & 0.08187 \\
\hline 40 & 0.08995 & 0.11878 & 0.12486 & 0.17764 & 0.15607 & 0.17468 & 0.11929 & 0.16137 & 0.10740 \\
\hline 60 & 0.09035 & 0.11878 & 0.16703 & 0.19782 & 0.17982 & 0.19380 & 0.16596 & 0.18714 & 0.13623 \\
\hline 80 & 0.13211 & 0.14668 & 0.24473 & 0.20944 & 0.19398 & 0.20469 & 0.18486 & 0.20473 & 0.13837 \\
\hline 100 & 0.13818 & 0.15047 & 0.23451 & 0.21646 & 0.20357 & 0.21308 & 0.20101 & 0.22017 & 0.14485 \\
\hline
\end{tabular}

Table 5.2.c Avg. End-to-End Delay.

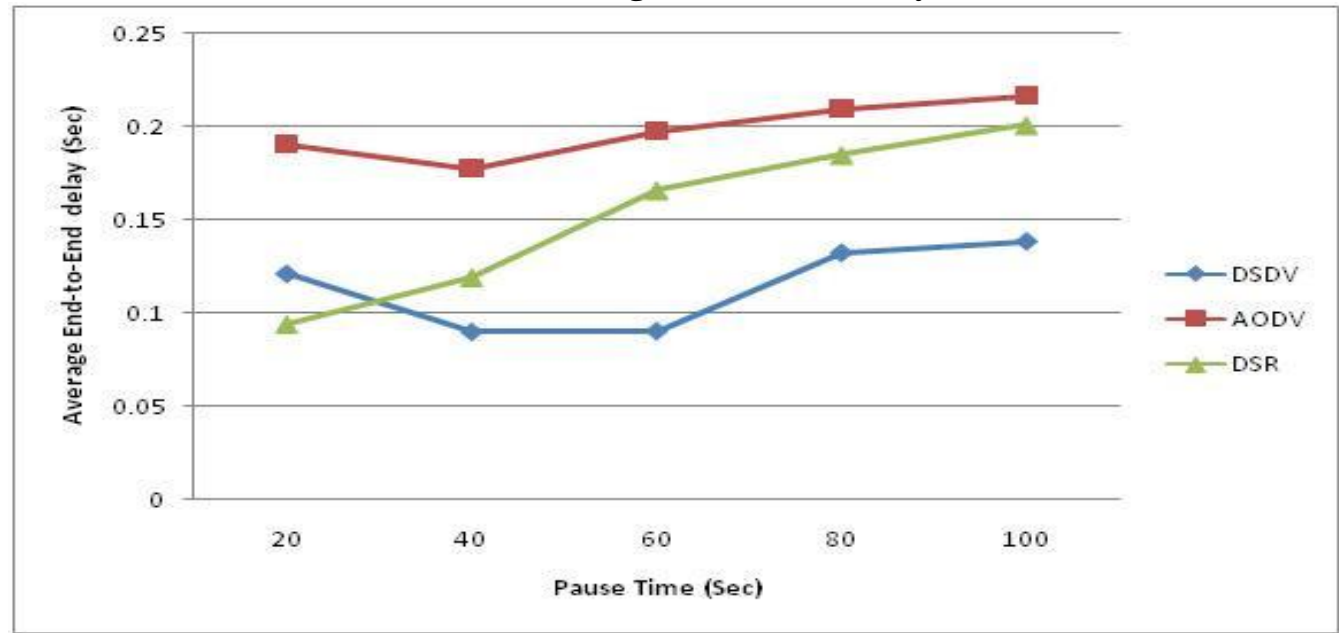

Graph no. 5.2.c Avg. End-to-End Delay

Volume 4 Issue 11, November 2015

www.ijsr.net 


\section{Solution to the Black Hole Problem}

One conceivable answer for the dark gap problem is to handicap the capacity to answer in a message of a middle of the road hub, so all answer messages ought to be conveyed just by the destination country hub. Utilizing this system the intermediate hub can't answer, so in some sense we stay away from the dark opening issue and actualize a secured AODV convention. In any case, there are two related inconveniences. Initially, the steering intercede hub. Along these lines, we stay away from the circumstance of the middle hub making further move, for example, manufacturing the answer message in the interest of the following jump hub. At the point when the source hub gets t1he Further Reply from the next hop, it extricates the check result from the answer parcels. In the event that the outcome is yes, we build up a course to the destination and start to send out data bundles. On the off chance that the next hop has no course to the asked middle of the road hub, however has a course to the destination hub, we toss the answer pack-etc from the asked moderate hub, and use the new course through the next hop to the destination. In the meantime, convey the caution message to the entire system to detach the malevolent hub. In the event that the next hop has no course to the asked for middle of the road hub, and it likewise has no course to the destination hub, the source hub starts another directing disclosure procedure, furthermore conveys a caution message to disconnect the malevolent hub.

\section{Summary \& Conclusions}

This work explored various routing protocols existing in MANETs. The energy consumption behavior of various routing protocols is being analyzed. With energy optimization proper delivery of packets with optimum cost is also concerned. Thus, Energy that is to be consumed by the nodes in transmitting a message can be estimated and packets may be distributed both in case of On-Demand and table driven transmission. In table driven transmission the energy can be estimated while prior load distribution and in case of on demand a packet can be send as acknowledgement after examining the energy consumption at a particular node while sending a long information.

In addition, ad hoc routing requires that nodes cooperate in forwarding each other's packets through the network. This means the throughput available to each single node's applications is limited not only by the raw channel capacity, but also by the forwarding load imposed by distant nodes. This effect could seriously limit the usefulness of ad hoc routing. One serious question is that why the nodes should cooperate in forwarding traffic to other nodes when there is no benefit.

A MANET consists of autonomous, self-organizing and self-operating nodes, each of which communicates directly with the nodes within its wireless range or indirectly with other nodes via a dynamically computed, multi-hop route. Due to its many advantages and different application areas, the field of MANETs is rapidly growing and changing. While there are still many challenges that need to be met, it is likely that MANETs will see wide-spread use within the next few years.

In order to facilitate communication within an MANET, an efficient routing protocol is required to discover routes between mobile nodes. Energy efficiency is one of the main problems in an MANET, especially in designing a routing protocol. In this paper, we surveyed and classified a number of energy-aware routing schemes. In many cases, it is difficult to compare them directly since each method has a different goal with different assumptions and employs different means to achieve the goal. For example, when the transmission power is controllable, the optimal adjustment of the power level is essential not only for energy conservation but also for the interference control. The study reveals that, DSDV routing protocol consumes more bandwidth, because of the frequent broadcasting of routing updates. While the AODV is better than SDV as it doesn't maintain any routing tables at nodes which results in less overhead and more bandwidth. From the above, chapters, it can be assumed that DSDV routing protocols works better for smaller networks but not for larger networks. So, my conclusion is that, AODV routing protocol is best suited for general mobile ad-hoc networks as it consumes less bandwidth and lower overhead when compared with DSDV routing protocol. In quantitative analysis AODV version with only hello messages has lowest delay on the data packets that are received, so AODV is better. AODV with hello message and hello-MAC layer are support how a slightly lower delay than AODV-MAC means this protocol completely support on-demand. Where as in qualitative both DSR versions and the AODV versions with link layer support have almost identical throughput. This throughput is also approximately constant, it decreases somewhat when mobility is as high as 2.5 to 3.5. Finally AODV with only hello message and DSDV have a throughput that drastically decreases when mobility increases. AODV with only hello show a very poor result.

\section{References}

[1] Can J.C. and Manzoni P. (2000) "A performance comparison of energy consumption for Mobile Ad hoc Networks routing protocols"; pp1-8.

[2] Chansu Y.(2012) "Energy efficient routing protocols for mobile ad hoc networks" vol 2; pp 29-67.

[3] Chin K. and John J. (2012) "Implementation Experience with MANET Routing Protocols" vol 2; pp-17-45.

[4] Deepa S. (2008) "A Study on the Behavior of MANET Routing Protocols with Varying Densities and Dynamic Mobility Patterns" vol 2; pp 67-90.

[5] Dr. Dhenakaran S.S. (2011) “An Overview of Routing Protocols in Mobile Ad-Hoc Network" vol 4; pp 6580.

[6] Garg N. and Mahapatra R.P. (2009) "Mobile Ad hoc Network Security Issues" vol 9; pp 241-246.

[7] Gorantala K. (2012) "Routing Protocols in Mobile Ad-hoc Networks" vol 2; pp 78-87. 


\section{International Journal of Science and Research (IJSR) \\ ISSN (Online): 2319-7064 \\ Index Copernicus Value (2013): 6.14 | Impact Factor (2014): 5.611}

[8] Haas Z. J. and Papadimitratos P. (2002) "Secure Routing for Mobile Ad Hoc Network"; pp 1-13.

[9] Iyengar N.S. (2010) "An Efficient and secure routing protocol for mobile ad hoc networks" vol 2; pp 28-36.

[10] Kaur J. and Dr.Harit S. (2015) “An Energy Efficient Secure and Trust Aware routing protocol in MANET" vol 5; pp 219-223.

[11]Laura M.F. (2010) “A Taxonomy for Routing Protocols in Mobile Ad Hoc Network" vol 3; pp 7898.

[12] Le P.H. (2015) "Performance analysis of interference aware routing protocol for mobile ad hoc networks" vol 4; pp 1-5.

[13]Lundberg J. (2000) "Routing Security in Ad hoc Networks"; pp 1-12.

[14] Manickam P. and Baskar G. T. (2011) "performance comparisons of routing protocols in mobile ad hoc networks" Vol 3; pp.-112-134.

[15] Mohammad S. and Ansar S. (2010) "An Efficient and Secure Routing Protocol for Mobile Ad-Hoc Network" vol 2; pp.-24-45.

[16] Nagaratna M. (2011) "Performance Evaluation of Mesh - Based Multicast Routing Protocols in MANET's" vol 2; pp 129-156.

[17] Nayak K. and Gupta N. (2015) "Energy efficient consumption based performance of AODV,DSR and ZRP Routing protocol in Mobile Ad hoc Network" vol 4; pp 82-90.

[18] Olagbegi B. S. and Meghanathan N. (2010) "A Review of the energy efficient and secure multicast routing protocol for mobile ad hoc networks" vol 2; pp1-15.

[19]Pandey K. and Swaroop A. (2011) "A Comprehensive Performance Analysis of Proactive, Reactive and Hybrid MANETs Routing Protocols" vol 8, Issue 6.

[20] Patil V.P (2012) "Efficient AODV Routing Protocol for MANET with enhanced packet delivery ratio and minimized end to end delay" vol 2, Issue 8.

[21] Ramasubramanian V. (2010) "SHARP: A Hybrid Adaptive Routing Protocol for Mobile Ad Hoc Networks" vol 2; pp 67-89.

[22]Reddy R. K. and Venkata R. S. (2012) "Reactive, Proactive MANET Routing Protocol Comparison vol" vol 12; pp-132-156.

[23] Sadawarti H. and Verma A. K. (2011) "Review of Various Routing Protocols for MANETs" vol 2; pp.45-59.

[24] Shrivastava A. (2005) "Overview of Routing Protocols in MANET's and Enhancements in Reactive Protocols" vol 3; pp 56-89.

[25] Singh A.and Chadha D. (2013) "A Study on Energy Efficient Routing Protocols in MANETs with Effect on Selfish Behavior" vol 3; pp.-13-27.

[26] Singh D.S. and Singh D. (2012) "Performance Analysis and Simulation of AODV, DSR and TORA Routing Protocols in MANETs" vol 1, Issue-3.

[27] Singh M. C. and Joon R. (2012) "Simulation and Comparison of AODV, DSR and AOMDV Routing Protocols in MANETs" vol 2, Issue-3.

[28] Taneja S.and Kush A. (2012) "Energy Efficient secure and stable routing protocol for Mobile AD hoc Network" vol 12;pp 1-15.
[29] Tao L. (2009)" Mobile Ad-hoc Network Routing Protocols: Methodologies and applications" vol 3; pp 43-67.

[30] TSENG Y.C. (2012) "Mobile Ad Hoc Networks and Routing Protocols" vol 3; pp 67-89.

[31] Yadav V. and Singh A.V. (2013) "Fast and secure routing protocol in Mobile Ad hoc network" vol 13; pp 1-5.

[32] Yang H. and Luo H.(2014) "Security in Mobile Ad hoc Networks challenges and solutions" vol 4; pp 3847. 